\title{
LA COMPETENCIA CONSULTIVA DEL TRIBUNAL PERMANENTE DE REVISIÓN DEL MERCOSUR: LEGITIMACIÓN Y OBJETO
}

\section{A COMPETÊNCIA CONSULTIVA DO TRIBUNAL PERMANENTE DE REVISÃO DO MERCOSUL: LEGITIMIDADE E OBJETO}

\section{Raphael Carvalho de Vasconcelos ${ }^{* *}$ \\ Sergio Maia Tavares ${ }^{*}$}

Resumen: La investigación busca esclarecer el régimen jurídico de las Opiniones Consultivas, observando tanto las normas del derecho de la integración, como las reglamentaciones internas de los Estados-miembros. En especial, aborda las modalidades del mecanismo consultivo y la cuestión de quiénes tienen legitimación para valerse de él. Refleja las aparentes diferencias entre las normas indagando y explicando la preservación de la coherencia del sistema en contexto de pluralidad de agentes jurídicos promotores de la ciudadanía del MERCOSUR

Resumo: A investigação busca esclarecer o regime jurídico das Opiniões Consultivas, observando tanto as normas do direito da integração, como as regulamentações internas dos Estados-membros. Em especial, aborda as modalidades do mecanismo consultivo e a questão dos legitimados a se valer dele. Reflete as aparentes diferenças entre as normas, provocando e explicando a higidez do sistema diante da pluralidade de agentes jurídicos promotores da cidadania mercosulina.

\footnotetext{
* El artículo conforma versión ampliada y en castellano del texto presentado en portugués para publicación en el XII Congreso Brasileiro de Direito Internacional.

** Magister y Doctor por la Universidad de San Paulo, Magister y Doctor por la Universidad del Estado de Rio de Janeiro, profesor de licencia de la Universidad Federal Rural de Río de Janeiro, cumple actualmente el mandato brasileño en la Secretaría del Tribunal Permanente de Revisión del MERCOSUR, Abogado.

*** Miembro del Laboratorio de Estudios en Derecho Constitucional Latino-Americano, en la línea de Derecho Constitucional Internacional y Comparado, de la Facultad de Derecho - Universidad Federal Fluminense (PPGDC), donde es investigador con énfasis al Derecho del MERCOSUR y de la integración. Estudió en la Facultad de Derecho de la Universidad de Coimbra, bajo el programa de movilidad entre estas instituciones, dedicándose a la investigación del Derecho de la Unión Europea. Estudiante de post- grado de la Escuela de la Magistratura del Estado de Río de Janeiro - EMERJ. Abogado.
} 
Palabras clave: Tribunal Permanente de Revisión, Opiniones Consultivas, Régimen Jurídico

Palavras-chave: Tribunal Permanente de Revisão, Opiniões Consultivas, Regime jurídico

\section{INTRODUCCIÓN}

Este artículo busca identificar el sistema de las Opiniones Consultivas en el derecho del MERCOSUR y evaluar las posibles tensiones generadas por las aparentes dicotomías y discrepancias en la regencia del tema por las reglas regionales y por los ordenamientos jurídicos nacionales.

Desde el Protocolo de Olivos - celebrado en 2002 y vigente en 2004 - que derogó el Protocolo de Brasilia y sustituyó el sistema regional de solución de controversias, el MERCOSUR viene experimentado grandes avances institucionales.

El impacto más significativo se hizo sentir con el establecimiento del Tribunal Permanente de Revisión, el 13 de agosto de 2004 en Asunción, capital del Paraguay y considerada hoy el centro jurídico del MERCOSUR. Con sede en la histórica Villa Rosalba, flanqueado por el Estado Mayor General y el Ministerio de Defensa, la mansión albergó hasta 1987 el despacho de Alfredo Stroessner a lo largo del gobierno dictatorial que él presidió.

En efecto, la morada jurisdiccional mercosureña reafirma y simboliza, en buena medida, los vectores de la integración regional de América del Sur: la reconstrucción democrática de los Estados miembros; la búsqueda de la estabilidad política; el derecho al desarrollo; la consagración de los derechos humanos; el crecimiento económico con expansión de los mercados ${ }^{1}$.

Sin embargo, la instalación de TPR revistió otro significado relevante. Expresó la elección - aún en sus primeros pasos - de seguir el

\footnotetext{
1 Era preciso superar el siguiente cuadro: "Simon Bolívar lo ha expresado con filo de bisturí: 'En América no hay fe entre los hombres y sus naciones. Los tratados son papeles; las constituciones, libros; elecciones son combate; libertad, anarquía. Y la vida un tormento'. En conclusión, predomina en nuestra mentalidad un individualismo poco fecundo, porque estimula una incesante hostilidad que impide acercar hombros y reconocer en el otro un modelo, un colega o un auxiliar. Tenemos dificultades serias para trabajar asociados" (AGUINIS, 2003). Así, "as novas orientações e exigências fizeram com que os Estados partes do Mercosul vejam na integração um instrumento no qual depositar as esperanças de uma sociedade mais humana, comprometida em construir um mundo mais solidário no século XXI (...). O início desse processo, que culminou com a assinatura do Tratado de Assunção, caracteriza-se por várias semelhanças políticas e econômicas entre a Argentina e o Brasil (...), cuja solução era mais fácil no quadro de uma estreita colaboração e cooperação. (...) Acima de tudo, era crucial romper a lógica realista de equilíbrio do poder vigente até aquele momento e aceitar a máxima 'se tudo está bem para meu vizinho, isso influi positivamente em meu próprio bem-estar"” (OCAMPO, 2009).
} 
camino de la integración por el derecho (Vauchez, 2008). En ese orden de ideas, se destaca en medio de otros, que "o aspecto decisivo da efetividade de proteção dos direitos reside na existência de um tribunal, dotado de jurisdição obrigatória e que possa ser acionado por iniciativa direta dos titulares dos direitos alegadamente violados" (DUARTE, 2010, p. 93).

En otras palabras, se trata del acceso a la justicia integracionista. El control jurisdiccional, o mejor dicho, la posibilidad de desencadenarlo determina la inclusión de los ciudadanos en primer plano dentro del proyecto regional, en que impera el derecho (Rechtsstaat).

Además de los expedientes contenciosos, las herramientas procesales consultivas son los mecanismos consagrados por el derecho de la integración para tal efecto.

En el MERCOSUR, fueron creadas las Opiniones Consultivas ${ }^{2}$. Consisten en una herramienta de comunicación dialógica directa entre el TPR y los Estados-miembros o los órganos mercosureños con capacidad decisoria; o por otro lado, de cooperación inter-jurisdiccional entre órgano jurisdiccional máximo del sistema de integración (TPR) y los tribunales superiores de los Estados-miembros.

Aunque no se puede clasificar el TPR como "poder" judicial de la integración, teniendo en cuenta su naturaleza arbitral, las OC apuntan a un horizonte interesante. Pasemos a su análisis, a fin de observar como la normativa MERCOSUR y las reglamentaciones nacionales rigen la materia, problematizando en especial las hipótesis acerca de la legitimación activa de los particulares y la extensión del objeto de las OC. Son esos, pues, los objetivos de este artículo.

\section{CUADRO NORMATIVO DEL DERECHO DEL MERCOSUR}

En la aplicación del derecho regional, las instituciones y órganos regionales y/o las jurisdicciones nacionales pueden enfrentar cuestiones (puntos controvertidos o dudas) de interpretación o de validez al respecto de las normas del sistema jurídico-legal de la integración en el curso de las relaciones procesuales. Con el fin de abordar y de crear una relación cooperativa entre el juez nacional y el TPR, más allá de promover la armonización ${ }^{3}$ del derecho mercosureño, el sistema de Olivos instituyó

2 En la Unión Europea, hay Reenvío prejudicial, cuyas características son bastante distintas. Sobre ese punto, ver: ABRUNHOSA Olívia Waldemburgo e TAVARES Sergio Maia. Cooperação interjurisdicional: ferramentas interlocutórias e modalidades na União Europeia. Da cooperação na Iberoamérica e no Mercosul ao gradual federalismo do Espaço Judicial Europeu. In: Revista do Instituto do Direito Brasileiro (IDB-FDUL). Lisboa: n. 12, 2013, p. 13147-13193.

3 Sin las Opiniones Consultivas, el margen para los diferentes tribunales nacionales de todos los poderes y autoridades de cada Estado miembro de decidir de manera diferente e incluso contradictoria sería alto. Con las OCs, el TPR se convierte en el garante de la aplicación armónica del derecho mercosureño, estableciendo la lectura normativa de las disposiciones de la integración. La aplicabilidad del derecho regional no puede variar de un estado a otro a 
las OCs. Los jueces nacionales de los Estados-miembros son plenamente competentes para hacer valer el derecho del MERCOSUR y al TPR le cumple determinar el sentido y el alcance de sus disposiciones. Por eso, se reitera, en la apreciación de las OC, que la intervención del TPR no tiene carácter contencioso.

Describe el artículo $3^{\circ}$, del Protocolo de Olivos:

Artículo 3 - Régimen de solicitud. El Consejo del Mercado Común podrá establecer mecanismos relativos a la solicitud de opiniones consultivas al Tribunal Permanente de Revisión definiendo su alcance y sus procedimientos.

Sin más detalles, la eficacia de la norma primaria es, evidentemente, condicionada a regulación propia, que fue establecida inicialmente por la Decisión CMC N. 37/2003. Dicha normativa estableció el Reglamento del Protocolo de Olivos para la Solución de Controversias en el MERCOSUR.

El Capítulo II del Reglamento dispuso acerca de la ordenación y reglamentación de las OCs. En los artículos del 2 al 13 se establece su régimen jurídico. Las tres primeras disposiciones versan sobre la legitimidad para la solicitud y la materia a ser resuelta, esto es, dictaminan quienes pueden solicitar una Opinión Consultiva y cuál debe ser el objeto de la solicitud.

De esa manera, se lee en el artículo 3ro. del Reglamento que son legitimados: todos los Estados - miembros, actuando conjuntamente; el Consejo del Mercado Común (CMC); el Grupo del Mercado Común (GMC); y la Comisión de Comercio del MECOSUR (CCM). Para estos sujetos, la OC puede abordar, conforme el texto legal, cualquier cuestión jurídica comprendida en el Tratado de Asunción, el Protocolo de Ouro Preto, los protocolos y acuerdos celebrados en el marco del Tratado de Asunción, las Decisiones del CMC, las Resoluciones del GMC y las Directivas de la CCM.

Si fuera un Estado miembro (o más de uno) quien desea requerir, debe ser elaborado un proyecto de solicitud, que se presentará a los demás miembros, a fin de formar un consenso sobre el objeto y el contenido. Ausente el consenso, no se promueve la solicitud. Habiendo consenso, la Presidencia Pro Tempore presentará la solicitud a la Secretaría del TPR.

Si la OC es requerida por un órgano del MERCOSUR, la solicitud debe incluir el acta de la reunión en la que se decide a hacerlo. De igual manera, seguirá el procedimiento a través de la PPT.

Ya en el artículo 4, es la regencia de la solicitud de la Corte Superior del Estado miembro que ejerce la jurisdicción de ámbito nacional. Es decir, se observa aquí la modalidad de la cooperación jurídica

merced de la legislación interna. 
internacional / interjurisdiccional en un movimiento desde los órganos que ejercen la función judicial interna hacia la cúpula jurídica regional.

En esta hipótesis, las OCs se limitan a cuestiones de interpretación de la normativa del MERCOSUR y el trámite de envío de la solicitud seguirá lo establecido por los tribunales superiores nombrados en la DEC / CMC N o 02/2007, analizados más adelante.

También compete al Estado miembro determinar cuál es el tribunal superior con jurisdicción nacional, si hay más de uno, hará la solicitud. Es importante señalar que no excluye la posibilidad de una competencia concurrente, por lo que más de un tribunal superior de un Estado miembro podría tener dicha atribución sin prejuicios.

Adelante, el artículo 5 de la RPO fija la forma de presentación.

Artículo 5 - Presentación de la solicitud de opiniones consultivas. En todos los casos, la solicitud de opiniones consultivas se presentará por escrito, formulándose en términos precisos la cuestión respecto de la cual se realiza la consulta y las razones que la motivan, indicando las normas del MERCOSUR vinculadas a la petición. Asimismo deberá acompañarse, si correspondiere, toda la documentación que pueda contribuir a su dilucidación.

Su lectura debe ser combinada con el artículo $9^{\circ}$, que diseña el "formulario" en términos de contenido de la presentación.

Artículo 9. Contenido de las opiniones consultivas 1. Las opiniones consultivas se fundarán en la normativa mencionada en el artículo 34 del Protocolo de Olivos y deberán contener: a. una relación de las cuestiones sometidas a consulta; $b$. un resumen de las aclaraciones de los solicitantes, si el Tribunal las hubiese pedido; c. el dictamen del TPR con la opinión de la mayoría y las opiniones en disidencia, si las hubiera. 2. Las opiniones consultivas serán fundadas y suscritas por todos los árbitros intervinientes.

Los artículos $6^{\circ}, 7^{\circ}$ y $8^{\circ}$ del Reglamento describen acerca del funcionamiento, de la composición plenaria, de eventual agilización del plazo (con la alteración de la DEC/CMC N.15/2010) del TPR para el examen de la Opinión Consultiva. El proceso consultivo será concluido, en la forma del artículo 10, de modo positivo con la emisión de la Opinión; y, de modo negativo, con la comunicación de no emisión por inadmisibilidad o con el inicio del procedimiento contencioso. El artículo 12 aclara las causas de inadmisibilidad.

Por último, el artículo 11 de RPO encierra la sistemática consultiva en el documento, afirmando los efectos del pronunciamiento del TPR por OC. Las opiniones consultivas emitidas por el TPR no serán 
vinculantes ni obligatorias. Es esa, pues, su gran fragilidad.

Sin embargo, la ya aludida DEC/CMC N. 02/2007 hizo explicitas las condiciones para que los tribunales superiores solicitasen la Opinión Consultiva del TPR. En ella, se determinó que la Corte Suprema de Justicia de la Nación (por Argentina), el Supremo Tribunal Federal (por Brasil), la Corte Suprema de Justicia (por Paraguay) y la Suprema Corte de Justicia y el Tribunal de lo Contencioso Administrativo (por Uruguay) son los competentes para requerir tal modalidad de OC. Venezuela aún no reglamentó la materia.

Referida competencia es delegable, conforme el artículo $3^{\circ}$ de la normativa, desde que se ha cumplido el requisito del ejercicio de la jurisdicción nacional por el tribunal delegante. La Decisión 02/2007 reitera los elementos formales y materiales esenciales que deben constar en la solicitud y reafirma que su objeto es limitado en este tipo de OC y se concentra en la interpretación jurídica de las normas del MERCOSUR.

\section{MARCONORMATIVO DEREGLAMENTOS DELOS TRIBUNALES SUPERIORES NACIONALES}

En cuanto a la modalidad de OC solicitada por los órganos del MERCOSUR, no existen grandes dilemas. Los puntos centrales de este estudio derivan de la normativa interna de los tribunales nacionales superiores en lo que se refiere a esta especie de OCs. Para apreciar tales puntos, se hace necesario observar, antes, el texto de las referidas reglamentaciones locales.

En orden cronológico, la inaugural Acordada 7604/2007, de la Suprema Corte de Justicia del Uruguay, establece que si fuera suscitada una duda acerca de la validez o de la interpretación de la normativa MERCOSUR ante cualquier órgano del Poder Judicial, tal órgano podrá requerir OC, debiendo despachar a la SCJ la solicitud hecha (artículos $1^{\circ}$ y $2^{\circ}$ ). Cuando no mencione que sujeto podrá suscitar la duda, la teoría de la relación procesual enseña que la misma puede surgir de oficio o a pedido ${ }^{4}$.

Cumplidos todos los requisitos previstos por las normas MERCOSUR y reproducidos en los reglamentos internos, el artículo $4^{\circ}$ pondera la solicitud al TPR en remisión directa - lo que también

$4 \mathrm{Al}$ respecto del interés de la parte en suscitarla, son dispensadas elaboraciones; al respecto del juez suscitarla, se señala: "Com efeito, a solução de certa questão pode influenciar a de outra: (a) tornando dispensável ou impossível a solução dessa outra; ou (b) predeterminando o sentido em que a outra há de ser resolvida (...) ter-se-á uma condição necessária, mas não suficiente" (MOREIRA, 1967). Se impone la actuación de ofício para actualizar la prestación jurisdiccional. En otras palabras, "por vezes, uma relação jurídica diversa daquela que compõe a causa de pedir, não obstante esteja fora da órbita da decisão da causa, precisa ser apreciada como premissa lógica integrante do itinerário do raciocínio do juiz, antecedente necessário ao julgamento. Saltar sobre ela significaria deixar sem justificativa a conclusão sobre o pedido" (FUX, 2004). 
permite inferir la posibilidad de ser sometida a pedido de parte.

En el resto, se ocupa de los aspectos formales y de estilo.

Por medio de la Acordada N. 13/2008, la Corte Suprema de Justicia de la Nación Argentina aprobó las reglas para el procesamiento interno para el envío de las solicitudes de OC.

En el primero de sus ocho artículos, el documento dispone que todos los jueces del país, de jurisdicción nacional o provincial, podrán formular la solicitud sobre interpretación del derecho mercosureño en el marco de una causa en trámite de su esfera de competencia, sea resultado tanto por medio de requerimiento de parte, como una manifestación de oficio indistintamente.

El artículo $4^{\circ}$ define el rito de la solicitud: el tribunal de primera instancia envía la formulación a la corte superior competente para la materia y ésta la transferirá a la CJSN, que, después de verificar los requisitos de admisibilidad, lo remitirá al TPR.

En síntesis, reitera las formalidades y el contenido que deben ser respetados por las solicitudes.

La Acordada 549/2011, de la Corte Suprema de Justicia de Paraguay, retomando la lógica adoptada en el Uruguay, expresa que ante cualquier tribunal del país puede ser suscitada una duda en cuanto a la validez o interpretación jurídica de la normativa MERCOSUR. El referido órgano remite la solicitud para la Dirección de Asuntos Internacionales de la Corte Suprema de Justicia (artículos $1^{\circ}$ y $2^{\circ}$ ). No es explícita acerca de la legitimidad, con todo ello, en la relación procesal, una duda puede ser planteada por el juez, como por las partes.

En el resto, trata de las formalidades del pedido y de los ítems obligatorios de contenido (art. $4^{\circ}$ ) y asevera que, cumplidos los requisitos, la CSJ decidirá sobre la pertinencia del pedido y lo enviará directamente al TPR $\left(\right.$ art. $\left.5^{\circ}\right)$. En el que, pese a la decisión sobre la pertinencia, la expresión "enviará directamente" transmite la idea de vinculación.

En Brasil, el "Regimento Interno" del Supremo Tribunal Federal fue alterado por la Enmienda 48/2012 para acoger el procedimiento de las OCs. El artículo 354-H fue insertado y establece que la solicitud de Opinión Consultiva debe necesariamente originarse del proceso promovido ante la justicia brasileña y "se restringe exclusivamente a la vigencia o interpretación jurídica" del derecho integracionista (destacado).

En el artículo 354-I queda muy clara la legitimidad activa ampliada por el RISTF. Pueden requerir al STF el envío de la solicitud de OC al TPR el juez de la causa o alguna de las partes.

Con el tiempo, los artículos 354-K e 354-L demuestran la naturaleza de la decisión del STF (vinculada y administrativa), teniendo en cuenta que la deliberación se celebrará en sesión administrativa de la Corte para simple verificación del cumplimiento de los requisitos de 
admisibilidad. Si presente, la solicitud se envía automáticamente. A lo sumo, el documento reproduce los motivos formales y las indicaciones de contenido de la solicitud.

Por último, se menciona nuevamente que el MERCOSUR sigue esperando la regulación de Venezuela en ese ámbito.

\section{DENUEVO,LALEGITIMIDAD.ALFINAL,¿LOSPARTICULARES LA DETENTAN?}

En efecto, después de las consideraciones hechas más arriba, no quedan dudas de qué papel le corresponde a los tribunales superiores investidos de jurisdicción sobre todo el territorio del Estado-miembro, en armonía con la normativa MERCOSUR, es el de enviar la solicitud de Opinión Consultiva que será pronunciada por el Tribunal Permanente de Revisión. Se trata, por lo tanto, de una etapa no decisoria, pero de deliberación ${ }^{5}$.

Es cierto que si la cuestión surge en el curso de un proceso en trámite en el propio tribunal superior, este formulará el pedido $\mathrm{y}$, al mismo tiempo, será responsable por remitirlo al TPR.

Todavía, el tema central reside en averiguar si existe incongruencia entre el derecho de la integración y los reglamentos internos en el ámbito de la legitimidad para solicitar a las Cortes el envío de OCs.

La primera nota ya fue subrayada. La lectura jurídica técnica de la normativa MERCOSUR indica que los tribunales superiores detentan, en realidad, competencia para formular y enviar pedidos de OC. El derecho integracionista prevé la centralización, la concentración de la legitimidad para solicitar la opinión y, así, los tribunales superiores son las autoridades investidas de la atribución de consultar al TPR acerca de la mejor aplicación del derecho del MERCOSUR ${ }^{6}$.

El derecho mercosureño no apartó, aún así, la formulación de las Opiniones Consultivas de oficio por los jueces y por las instancias ad quem o por los ciudadanos. Determinó solamente que la solicitud es hecha por los tribunales superiores. Se observa, en ese punto, que todos los reglamentos internos de los tribunales indicados en la DEC./ CMC N. 02/2007 aseguraron de manera amplia a los miembros de las instituciones judiciales nacionales la competencia para solicitar la formulación de consultas en consonancia con los principios rectores de la integración y del derecho mercosureño.

5 La opción por el uso del término "delibação" en este trabajo, conforme fue adoptado por la doctrina brasileña, no establece marco definitivo. Cumple en registrar, por lo tanto, su empleo por la doctrina procesalista de Brasil también en referencia a la sentencia de mérito recursivo y la utilización con alguna frecuencia del vocablo "prelibação" como sinónimo de juicio de admisibilidad de un recurso.

6 Específicamente con respecto a la concentración, la consideración de este punto como positivo o negativo para la integración sería objeto de otro debate. 
Las normas MERCOSUR optaron por concentrar sus dispositivos en los tribunales superiores en relación a la solicitud de OCs. Así, en la presentación sobre otros juicios, ellas no podrían imponer a los Estados-miembros cualquier régimen de competencia. Se percibe, con ello, delante de la poca especificación del artículo $4^{\circ}$, DEC./CMC N.37/20037, que los tribunales superiores podrían hasta arrogarse competencia exclusiva. No lo hicieron, conforme resaltado, en beneficio de los principios fundamentales del proceso integracionista, pues el juez nacional debe ser reconocido como encargado de aplicar las disposiciones regionales y de asegurar su pleno efecto cotidiano ${ }^{8}$.

Los órganos judiciales locales desempeñan, por tanto, una función primordial para la integración. Así, si el MERCOSUR, por un lado, presentó la integración a los tribunales superiores, los Estadosmiembros, con sus tribunales superiores, trajeron a los jueces de instancias ordinarias dentro del proceso y de esa manera se construye, hoy, el derecho común'.

Igualmente, conviene reflexionar si habría algún fundamento en excluir a los particulares como sujetos activos de la generación de cuestiones que envuelvan dudas en torno al derecho del MERCOSUR. Debido a que es el ciudadano el destinatario de la integración, sujeto y titular del derecho internacional.

En ese sentido, se nota que la Acordada 7604/2007 de la corte uruguaya, pionera en la reglamentación de la materia, otorga, en su artículo 2, al órgano del poder judicial, en el cual el conflicto esté en trámite, la legitimidad para enviar a la Corte el pedido de solicitud de Opinión Consultiva. Se observa, de hecho, la opción de restringir la posibilidad de formulación de consulta a los órganos decisorios internos, aunque su redacción no impida, entiéndase, que lo particulares provoquen al magistrado y soliciten el referido envío. Las consideraciones aquí hechas acerca de la tramitación del pedido en el poder judicial del Uruguay son aplicadas a lo establecido en la Acordada 549/2011 de la

7 La redacción podría incluir que la formulación de Opinión Consultiva es atribuida a todos los jueces de oficio y / o a las partes a pedido.

8 Los tribunales superiores y el TPR son conscientes de que sus decisiones son exigibles sólo si respaldadas por los tribunales nacionales.

9 "En Europa, todo juez nacional es al mismo tiempo juez comunitario, por la unidad existente entre el derecho comunitario y el derecho interno. En el Mercosur no se dice nada sobre esto, lo que constituye una grave omisión en un proceso de esta naturaleza" (DERMIZAKY PEREDO, 2004). Ver, entre otros, sobre la relación entre jueces nacionales y jueces de integración: BURLEY, Anne-Marie e MATTLI, Walter. Europe before Court: a political theory of legal integration. In: International Organization. Cambridge: CUP, v. 47, issue 01, dez., 1993, pp. 41-76; MAYER, Franz C. The European Constitution and the courts - adjudicating European constitutional law in a multilevel system. In: WHI Paper. Berlim: HumboldtUniversität, n.15/03, out. 2003, pp. 01-46; MADURO, Miguel Poiares. A Constituição plural. Constitucionalismo e União Europeia. Cascais: Principia, 2006; y el capítulo 1.3 de MAIA TAVARES, Sergio. Entre a compleição federalista e o constitucionalismo plural da União Europeia: teoria constitucional-internacional do pluralismo integracionista e do cidadão pósnacional. Niterói: s/e, FD-UFF, 2013. 
Corte paraguaya.

En cuanto a la norma argentina que garantizó el acceso a las Opiniones Consultivas - Acordada 13/08, esa no difiere substancialmente de las perspectivas reglamentares del Paraguay y del Uruguay, pero trae un elemento nuevo al contexto descripto. Luego en su artículo 1, quedó en forma expresa la posibilidad, que no se entiende vedada en Paraguay y en Uruguay, del miembro del poder judicial de ser provocado por la parte en el proceso para proceder al pedido de envío de la Opinión Consultiva. La reglamentación argentina, por tanto, no va más allá. Solamente establece dispositivo en lo que podría inferirse del sistema normativo.

En ese sentido, el RISTF trae novedades al versar explícitamente sobre la legitimidad de la parte para suscitar la cuestión y formular el pedido de OC. En la forma como está reglamentada en el Brasil la participación del particular en la solicitud se puede sostener, inclusive, que no tendría el juez de la causa discrecionalidad para decidir en relación al envío o no del pedido al STF.

En el proceso nacional, la naturaleza jurídica de la OC todavía está por ser revelada (si, por ejemplo, incidente procesal, si cuestión prejudicial, si sui generis - ya que no tienen carácter contencioso - u otro), pero lo cierto es que es causa de desestimación de la acción.

Así, es evidente que un particular regularmente integrado como parte procesal podrá formular pedido de Opinión Consultiva. También, debe prestarse atención a la forma de acceso del particular a la justicia mercosureña, en un movimiento evolutivo indispensable para que la integración siga teniendo al ciudadano en su núcleo.

La opción por la mención expresa de miembros del poder judicial o de particulares en los reglamentos de las cortes puede tener fundamento en el marco legal regional que, específicamente en el artículo 4 de la DEC/CMC 02/07, permite que la solicitud esté acompañada de las consideraciones formuladas por las partes en el litigio y por el Ministerio Público. Considerados tales aspectos, no habría motivos para no permitir la legitimidad del Ministerio Público para solicitar al poder judicial el envío de solicitud de Opinión Consultiva cuando no fuese parte en litigio. Todo eso, se resalta, aún no habiendo sido expresamente incluido en el rol de legitimados por ninguna de las reglamentaciones.

La ampliación de la legitimidad propiciada por los reglamentos nacionales en nada contradice la normativa MERCOSUR. Al contrario, la complementa, la refuerza y avanza rumbo a los objetivos más vigorosos del Tratado de Asunción, consistiendo un medio para futuros avances y vanguardismos mercosureños. Se percibe la retroalimentación entre derecho de la integración y derechos internos, que se articulan en un sistema único (monista) ${ }^{10}$, con relaciones plurales no jerárquicas basada

10 Tómese nota de que el derecho de la integración es parte del derecho interno. El derecho del 
en la preferencia de aplicación en concreto.

\section{INTERPRETACIÓN, VALIDEZ, VIGENCIA Y EL OBJETO DE LAS OPINIONES CONSULTIVAS}

El Protocolo de Olivos consigna en su artículo 3 que los procedimientos para la solicitud de Opiniones Consultivas y el alcance de las mismas sería establecido posteriormente por norma secundaria, específicamente por la actuación legislativa del Consejo Mercado Común.

El Reglamento del Protocolo de Olivos - anexo a la CMC/DEC 37/03 - completó la referida laguna normativa estableciendo en cuanto al alcance de la actuación jurisdiccional consultiva, en su artículo 3, que podrían ser solicitadas opiniones "sobre cualquier cuestión jurídica comprendida en el Tratado de Asunción, en el Protocolo de Ouro Preto, en los protocolos y acuerdos celebrados en el marco del Tratado de Asunción, en las Decisiones del CMC, en las Resoluciones del GMC y en las Directivas da CCM."11

La taxatividad del rol establecido por la decisión se muestra, con todo ello, apenas aparente. La referencia genérica a los instrumentos celebrados en el marco del Tratado de Asunción y la inclusión de todas las especies secundarias previstas en el Protocolo de Ouro Preto como hábiles para motivar solicitudes al TPR permiten que Opiniones Consultivas puedan tener como objeto una duda relacionada a toda y cualquier normativa que integre actualmente el sistema de derecho regional del MERCOSUR. Superada la cuestión del alcance de la normativa de la competencia consultiva del sistema de Olivos, es necesario verificar la amplitud de ese instrumento de armonización hermenéutica.

El artículo 3 del Reglamento del Protocolo se refiere a la legitimidad de los Estados y órganos de la Organización Regional sin fijar límites a la actuación de TPR en esos casos. El dispositivo siguiente, por otro lado, hace hincapié en que - cuando la consulta efectuada por Tribunales Superiores de Justicia - las opiniones emitidas regionalmente deberán hacer referencia "exclusivamente a la interpretación jurídica de la normativa MERCOSUR".

La solicitud de Opiniones Consultivas por los sistemas de justicia nacionales fue objeto, también, de reglamentación internacional

MERCOSUR es derecho nacional.

11 El rol establecido en la normativa secundaria fue reproducido ipsis litteris por las reglamentaciones nacionales de los tribunales superiores, a saber: en la República Oriental del Uruguay en virtud del artículo 1 de la Acordada 7604/07, la República Argentina por el artículo 1 de la Acordada 13/08, en Paraguay por el artículo 1 de la Acordada 549/08 y en Brasil en el artículo 354-H inserto en el Reglamento Interno STF por Enmienda regimental 48/12. Cabe señalar que la República Bolivariana de Venezuela aún no ha regulado el procedimiento. 
específica por medio del Reglamento del Procedimiento de Solicitud de Opiniones Consultivas por los Tribunales Superiores - RPSOC DEC/CMC 02/07, el cual reprodujo en su totalidad la limitación a la interpretación de la normativa regional.

Ahora, si los investidos de atribución legislativa establecieron en la norma secundaria regional una clara diferenciación entre el pronunciamiento consultivo provocado por Estados y órganos y aquél provocado por los tribunales superiores y, de manera bastante específica, fijó la exclusividad de la interpretación como estándar objetivo de las consultas, sería posible inferir que las reglamentaciones internas que sobrepasen tal parámetro podrían, ciertamente, permitir el envío al TPR de solicitudes, pero el órgano jurisdiccional debería, sin embargo, atenerse a lo previsto en los instrumentos internacionales.

Se observa, en relación a ello, que la primera reglamentación interna - Acordada 7604 de 2007 de la Suprema Corte de Justicia uruguaya - estableció la posibilidad de que los órganos judiciales requirieran el envío de la solicitud de OC al TPR en el momento, a partir de un caso concreto, del surgimiento de duda relacionada a la validez y a la interpretación jurídica de la normativa del MERCOSUR aplicable.

En el año siguiente, la Corte Suprema de Justicia de la Nación prescribió el procedimiento aplicable a las causas oriundas de tribunales argentinos en la Acordada 13 que, en su artículo 1, reproduce la literalidad de la restricción del RPO y del RPSOC limitando eventual consulta a dudas relacionadas a la interpretación del derecho regional.

En el mismo año 2008, la Corte Suprema de Justicia Paraguay procedió a la regulación de envío reproduciendo, a su vez, la normativa uruguaya y posicionó, por lo tanto, las dudas acerca de la validez de instrumentos normativos junto a la interpretación expuesta en la legislación secundaria regional como elemento motivador de consultas al TPR.

Brasil demoró bastante para viabilizar el acceso de la justicia nacional al instrumento consultivo y fue el último miembro de la organización regional en reglamentar, en 2012, el procedimiento por medio de la Enmienda Regimental 48, a la cual introdujo, entre otros, el artículo 354-H en el cuerpo del Régimen Interno del Supremo Tribunal Federal. Referido artículo fijó como objeto de duda pasible de motivar consulta a la esfera jurisdiccional regional la interpretación $\mathrm{y}$, desentonando con las reglamentaciones regionales y con las otras normativas internas, también cuestiones relacionadas a la vigencia del derecho del MERCOSUR.

Tres son, por lo tanto, las variaciones observables en la reglamentación de los procedimientos de envío de solicitud de opiniones consultivas al TPR con respecto al objeto de duda hábil de motivar la aplicación: la interpretación, validez y vigencia de la normativa del 
MERCOSUR.

Ajena a controversias se muestra la posibilidad relacionada al cuestionamiento hermenéutico. Las normas producidas interna $\mathrm{e}$ internacionalmente se refieren a esta hipótesis de manera uniforme. ¿Pero en cuanto a la validez y a la vigencia?

Es importante remarcar la diferencia conceptual establecida por la doctrina entre la validez y la vigencia de una norma jurídica. Validez, por un lado, se refiere al cumplimiento de los requisitos formales y materiales de producción legislativa. Vigencia, a su vez, nos remite a la dimensión temporal de la validez de un instrumento normativo. Un protocolo, por ejemplo, que dependa, en regla, del cumplimiento del procedimiento de internalización por los poderes legislativos de todos los Estados-miembros para tornarse aplicable, se encuentra válido cuando de la notificación a la Secretaría del MERCOSUR del cumplimiento del requisito por el último Estado-miembro, pero apenas estará vigente cuando transcurrido el plazo establecido para que sus instrumentos puedan ser aplicados.

Hechas las consideraciones necesarias, se nota que las acordadas paraguaya y uruguaya ampliaron la posibilidad de solicitud de OC al incluir en su espectro motivador dudas relacionadas a la validez de una norma regional, esto es, al cumplimento de requisitos formales y materiales para su ingreso en el ordenamiento jurídico. La normativa brasileña, por su parte, no hace referencia a la validez, pero si a la aplicabilidad de la norma en el tiempo.

En términos absolutamente estrictos, se observa claramente que el concepto de vigencia implica un análisis de validez de un instrumento y, por lo tanto, el Régimen Interno del STF hace referencia expresa a la interpretación y a la vigencia de la normativa regional e implícitamente, como también, a su validez ${ }^{12}$.

A partir del análisis superficial, se haría posible afirmar que los judiciales nacionales habrían sobrepasado los límites establecidos por la regulación regional al establecer a posibilidad de envío de consultas relacionadas a la validez y a la vigencia del derecho del MERCOSUR. Más que eso, sería el TPR, en esa línea de raciocinio, rechazar el envío de solicitud de OC motivada por duda cuanto al binomio validez/vigencia y, caso fuese provocada una controversia para discutir la reglamentación local, declarar su incompatibilidad con la normativa regional.

Tal entendimiento no debe prosperar. La investidura de un órgano decisorio en determinada competencia jurisdiccional posee como

12 "Validade é uma qualidade da norma que designa sua pertinência ao ordenamento, por terem sido obedecidas as condições formais e materiais de sua produção e conseqüente integração no sistema; [...] vigência é uma qualidade da norma que diz respeito ao tempo de validade, ao período que vai do momento em que ela entra em vigor (passa a ter força vinculante) até o momento em que é revogada, ou em que se esgota o prazo prescrito para sua duração" (FERRAZ JÚNIOR, 2003). 
presupuesto lógico la posibilidad de verificación de validez y de vigencia de norma que provoque o motive su pronunciamiento. En ese sentido, la emisión de una opinión consultiva por el TPR sobre la interpretación de norma inválida o sin vigencia representaría una incongruencia lógica inaceptable.

En otra hipótesis, se debe notar, todavía, que la eventual duda en cuanto a la validez o a la vigencia de un texto normativo regional implica un cuestionamiento claramente hermenéutico.

Vale subrayar un aspecto significativo. Las normas secundarias del derecho de la integración se someten al dúo "control" de las Opiniones Consultivas, de interpretación y de validez. A su turno, las normas primarias - es decir, los Tratados e Protocolos - están sujetos al control únicamente de interpretación, pues, evidentemente, consisten en el propio parámetro que afirma la (in)validez en tal tipo de OC.

Aunque la dicción de los artículos $3^{\circ}$ y $4^{\circ}$ del RPO no presenten transparencia absoluta en su contenido que demuestre esa substancia normativa, otro no puede ser su sentido. La verificación paramétrica presupone la oposición de normas cuyas naturalezas se distinguen.

Es cierto que esta relación se articula y acaece en el dominio del derecho regional internamente considerado. No se debe confundir con una jerarquía binaria de exclusión entre el derecho integracionista (en este caso, mercosureño) y los derechos nacionales. Ella no existe, por cuanto la relación aquí pronunciada se resuelve por la aplicabilidad material en concreto. Se tejen complementariedad y subsidiariedad en un esquema sistemático plural y no jerárquico.

Es importante resaltar que la consecuencia anulatoria sobre la normativa derivada propiciada por la OC carece de un recurso específico para ese fin dentro del ordenamiento jurídico del MERCOSUR. El TPR podrá declarar la invalidez de la norma a la luz del derecho primario dentro de los estrictos contornos de la duda suscitada y formulada en consulta. Eso no significa la exclusión de la norma del sistema jurídico, algo que sería posible si existiera recurso propio. Sin embargo, eso ya representa que, sin decidir el caso concreto motivador de la $\mathrm{OC}^{13}$, el TPR va fijando los márgenes dentro de los cuales se expresa el contenido de las normas del MERCOSUR al disponer, sanar y responder a la consulta.

De hecho, las reglamentaciones nacionales que tendrían supuestamente extendido la amplitud de la actividad jurisdiccional consultiva incurrieron, sobre tales parámetros, en mera redundancia al hacer mención a la interpretación y a la validez - o a la vigencia - de la norma que motiva la opinión consultiva.

13 Recuérdese que la OC no representa litigio para el juicio del TPR. No se trata de un desafío a la jurisdicción contenciosa de la Corte, aún si de la duda normativa, cuya apreciación deslindará a su vez los márgenes en que el caso concreto se resuelva ante la autoridad judicial competente. 
En lo que se refiere, por lo tanto, a la reglamentación del objeto del procedimiento consultivo - tal cual ocurre con la legitimidad subjetiva para provocarlo - no existe incongruencia entre el local y el regional en el contexto de gran pluralidad de órganos productores de normas involucrados.

\section{CONCLUSIÓN}

La creación de un instrumento de armonización de la aplicación del derecho del MERCOSUR representó un importante avance verificado en el Protocolo de Olivos y en sus normativas reglamentarias. La solicitud de Opiniones Consultivas al Tribunal Permanente de Revisión puede, así, servir para evitar el surgimiento de interpretaciones locales del derecho regional que puedan poner en peligro su coherencia sistémica.

Los cuatro miembros fundadores de la organización regional reglamentaron por medio del ejercicio de la función legislativa atípica - por órganos judiciales internos - el procedimiento de envío de solicitudes de consultas a la institución jurisdiccional de la organización internacional.

Del análisis de las disposiciones nacionales e internacionales que abordan el instrumento, se verifican dos dimensiones importantes: la legitimidad subjetiva para provocar las consultas y el alcance del pronunciamiento del tribunal arbitral permanente.

En lo que se refiere a la legitimidad, queda claro en las decisiones que reglamentan el Protocolo que, al lado de los Estados y órganos que integran el MERCOSUR, también los Tribunales Superiores nacionales poseen atribuciones de formular y enviar consultas. Referidos textos normativos no establecen en ningún momento, con ello, parámetros para la organización del orden judicial interno que establezca el nexo entre los casos concretos y las dudas que permitan la remisión de consultas al Tribunal Permanente de Revisión. En el caso brasileño, por ejemplo, el Supremo Tribunal Federal invistió miembros del Poder Judicial y también particulares con la legitimidad de solicitar la formulación de pedido de Opinión Consultiva.

No hay motivo jurídico para que se cuestione la participación directa del particular por medio de la vía consultiva en el sistema jurisdiccional del MERCOSUR. Más que eso, se trata de una clara contribución de los judiciales locales para aproximar la ciudadanía a la integración regional. Avance importante que merece, por lo tanto, ser remarcado.

En cuanto a la regulación de los objetos del procedimiento consultivo, se observa, a su vez, que las disposiciones regionales restringieron la amplitud del pronunciamiento consultivo a la 
interpretación del derecho del MERCOSUR. Obsérvese, mientras, que tres de las cuatro reglamentaciones internas hoy disponibles incluyeron, a lado de las dudas hermenéuticas, cuestiones relacionadas a la validez - vigencia en el caso brasileño - como pasibles de provocar envíos. Tal cual ocurre con la legitimidad subjetiva, el enfrentamiento de las reglamentaciones nacionales con la normativa regional no demuestra incongruencia jurídica de ninguna naturaleza.

La necesidad de participación de múltiples órganos en la producción de normas relacionadas al sistema de solución de controversias del MERCOSUR para crear y reglamentar la legitimación, demarcar el objeto y establecer los procedimientos de ese instrumento de armonización y hábil para promover el mantenimiento de la coherencia del derecho regional, representó un desafío muy bien superado por los involucrados. El sistema internacional mostró madurez y permanece, así, sano.

Resta ahora a los Estados, a los órganos de la organización y a los judiciales nacionales el reconocimiento de sus responsabilidades relacionadas a la integridad del marco jurídico internacional por medio de la utilización más frecuente de ese valioso instrumento. Las Opiniones Consultivas pueden convertirse en el importante primer paso para traer los diversos agentes jurídicos nacionales a la composición de la integración, esto es, hacia dentro del MERCOSUR. Así, se consolida el proceso de integración por el derecho (Rechtstaat), de forma tal que las construcciones políticas, como el MERCOSUR y todas las organizaciones regionales, se apoyen y tengan en el sistema jurídico - más de lo que en la economía por ejemplo - su fuerza propulsora; en protección a la ciudadanía, a los derechos fundamentales, las libertades públicas.

\section{REFERENCIAS BIBLIOGRÁFICAS}

ABRUNHOSA Olívia Waldemburgo e TAVARES Sergio Maia (2013) "Cooperação interjurisdicional: ferramentas interlocutórias e modalidades na União Europeia. Da cooperação na Iberoamérica e no Mercosul ao gradual federalismo do Espaço Judicial Europeu”. In: Revista do Instituto do Direito Brasileiro (IDB-FDUL). (12), p. 13147 13193.

AGUINIS Marcos (2003) El atroz encanto de ser argentinos. Buenos Aires: Planeta.

BURLEY Anne-Marie e MATTLI Walter (1993) "Europe before Court: a political theory of legal integration". In: International Organization. Cambridge: CUP, 47(1), p. 41-76.

DERMIZAKY PEREDO Pablo (2004) "Derecho constitucional, derecho internacional y derecho comunitario". In: Anuario de Derecho Constitucional Latinoamericano. México: Adenauer - UNAM. 
DUARTE Maria Luísa (2010) Estudos sobre o Tratado de Lisboa. Coimbra: Almedina, 2010.

FERRAZ JÚNIOR Tércio Sampaio (2003) Introdução do estudo do direito: técnica, decisão, dominação. São Paulo: Atlas.

FUX Luiz (2004) Curso de direito processual civil. Rio de Janeiro: Forense. GRANILLO OCAMPO Raúl (2009) Direito Internacional Público da Integração. Rio de Janeiro: Elsevier.

MADURO Miguel Poiares (2006) A Constituição plural. Constitucionalismo e União Europeia. Cascais: Principia.

MAYER Franz C. (2003) "The European Constitution and the courts - adjudicating European constitutional law in a multilevel system". In: WHI Paper. Berlim: Humboldt-Universität, 15/03, p. 01-46.

MOREIRA José Carlos Barbosa (1967) Questões prejudiciais e coisa julgada: tese de concurso para a docência livre de direito judiciário civil apresentada à congregação da faculdade de direito da UFRJ. Rio de Janeiro: Forense.

TAVARES Sergio Maia (2013) Entre a compleição federalista e o constitucionalismo plural da União Europeia: teoria constitucionalinternacional do pluralismo integracionista e do cidadão pós-nacional. Niterói: s/e, FD-UFF.

VAUCHEZ Antoine (2008) “Integration-through-Law' Contribution to a socio-history of EU political commonsense". In: EUI Working Papers. Florença: RSCAS, (10), p. 01-33. 
